\title{
The value of 'positive' clinical signs for weakness, sensory and gait disorders in conversion disorder: a systematic and narrative review
}

\author{
Corinna Daum, ${ }^{1}$ Monica Hubschmid, ${ }^{2}$ Selma Aybek ${ }^{1}$
}

- Additional material is published online only. To view this file please visit the journal online (http://dx.doi.org/ 10.1136/jnnp-2012-304607)

${ }^{1}$ Department of Neurology, Clinical Neurosciences Department, University Hospital (CHUV), Lausanne, Switzerland ${ }^{2}$ Psychiatric Liaison Service, Psychiatry Department, University Hospital (CHUV), Lausanne, Switzerland

Correspondence to Dr Selma Aybek, Department of Neurology, Clinical Neurosciences Department, University Hospital (CHUV), Service de Neurologie- BH13, Bugnon 44, Lausanne 1011, Switzerland;

selma.aybek@chuv.ch

Received 17 November 2012 Revised 23 January 2013 Accepted 5 February 2013
To cite: Daum C, Hubschmid M, Aybek S. J Neurol Neurosurg Psychiatry Published Online First: [please include Day Month Year] doi:10.1136/jnnp2012-304607

\section{ABSTRACT}

Experts in the field of conversion disorder have suggested for the upcoming DSM-V edition to put less weight on the associated psychological factors and to emphasise the role of clinical findings. Indeed, a critical step in reaching a diagnosis of conversion disorder is careful bedside neurological examination, aimed at excluding organic signs and identifying 'positive' signs suggestive of a functional disorder. These positive signs are well known to all trained neurologists but their validity is still not established. The aim of this study is to provide current evidence regarding their sensitivity and specificity. We conducted a systematic search on motor, sensory and gait functional signs in Embase, Medline, PsyclNfo from 1965 to June 2012. Studies in English, German or French reporting objective data on more than 10 participants in a controlled design were included in a systematic review. Other relevant signs are discussed in a narrative review. Eleven controlled studies (out of 147 eligible articles) describing 14 signs (7 motor, 5 sensory, 2 gait) reported low sensitivity of $8-100 \%$ but high specificity of $92-100 \%$. Studies were evidence class III, only two had a blinded design and none reported on inter-rater reliability of the signs. Clinical signs for functional neurological symptoms are numerous but only 14 have been validated; overall they have low sensitivity but high specificity and their use should thus be recommended, especially with the introduction of the new DSM-V criteria.

Conversion disorder (CD) is a disabling medical condition where patients present with a neurological symptom for which no medical explanation is found and which is interpreted as being rooted in a psychological origin. ${ }^{1}{ }^{2}$ The term 'conversion' derives from Freud's hypothesis of the conversion of a painful affect into a physical symptom, as a defence mechanism to unbearable emotional stressors. ${ }^{3}$ Hence in the current Diagnostic and Statistical Manual of Mental Disorders (DSM-IV) manual; the association of a functional, medically unexplained, neurological symptom (criterion A) with a psychological stressor (criterion B). There has been a recent debate ${ }^{4-6}$ about which diagnostic criteria should be retained in the future revised DSM-V, most of the controversy being about the role of psychological stressors and the differentiation with malingering (criteria D) arguing that both should disappear (DSM-V draft, http://www. dsm5.org). Thus, the adequate evaluation of the presenting neurological symptom and clinical findings play a crucial role. Indeed, the DSM-V task force proposed to introduce a new criterion stating that: 'clinical findings provide evidence of internal inconsistency or incompatibility with recognised neurological or medical disease'. This distinction is based on the exclusion of neurological signs pointing to a lesion of the central or peripheral nervous system, together with the identification of 'positive signs' known to be specific for functional symptoms. ${ }^{7}$

In the era of evidence-based medicine however, clinicians are facing a lack of proof regarding the validity of those clinical 'positive signs'. The majority of the commonly used signs rely on traditional knowledge and very few have been validated. ${ }^{8}$ Diagnostic criteria for movement disorders ${ }^{9}$ exist, reliable signs for non-epileptic seizures ${ }^{10}$ are available and both presentations have laboratory supportive criteria ${ }^{11} 12$ to help with diagnosis. Therefore we chose to focus here on clinical signs pertaining to weakness, sensory and gait disorders. The aim of this study is to provide a systematic review of the existing validated clinical 'positive signs' and report their specificity and sensitivity. In a narrative review we also critically discuss other described signs that have not been evaluated on objective criteria.

\section{METHODS}

\section{Search strategy}

The following databases were searched: Medline (from 1966), EMBASE (from 1980) and PsycINFO (from 1965) all to June 2012. Our search terms were: HYSTERIA, CONVERSION DISORDER, DISSOCIATIVE DISORDER, FUNCTIONAL DISORDER, NON-ORGANIC, PSYCHOGENIC, MEDICALLY UNEXPLAINED SYMPTOMS. They were combined with PARESIS, PARALYSIS, MOTOR SYMPTOM, MOTOR DEFICIT, HEMIPARESIS, HEMIPLEGIA, PARAPARESIS, PARAPLEGIA, WEAKNESS, SENSORY SYMPTOM, SENSORY DEFICIT, SENSORY LOSS, SENSITIVE, DERMATOMAL, GAIT, WALK, CLINICAL SIGN, PHYSICAL EXAMINATION, NEUROLOGICAL EXAMINATION, NEUROLOGICAL SIGN. Excluded were SEIZURES and EPILEPSY. Abstracts containing our search terms were sorted in a first screening and full-text articles were obtained using the defined inclusion criteria as far as possible (see below). The full-text articles were then selected in a second-stage screening using the inclusion criteria. Both steps were accomplished by two authors 
$(\mathrm{CD} / \mathrm{SA})$. The bibliographies of all articles were looked at and hand searching of pertinent journals was undertaken. An additional hand search for every single cited 'positive sign' was undertaken.

\section{Eligibility criteria}

Studies were included if they met the following criteria:

- Studying clinical signs on neurological examination in patients with hysteria/conversion disorder/dissociative disorder/functional disorder/non-organic disorder/ psychogenic disorder or medically unexplained symptoms presenting a motor or sensory deficit or gait disorder.

- Reports written in English, French or German.

- The participants were over 18 years.

- There were more than 10 participants in the study.

- A control group was available.

- An evaluation of sensitivity and specificity of a 'positive sign' was available.

- Minimum class III evidence level according to the classification scheme employed by the American Academy of Neurology.

Studies focused on factitious disorder, malingering or chronic pain were not considered, as well as studies focused on evoked potentials, transcranial magnetic stimulation (TMS) or functional magnetic resonance (fMRI). Studies evaluating movement disorders (tremor, dystonia, parkinsonism, etc), vertigo, deafness, blindness or other functional symptoms or signs were excluded.

\section{Data extraction and analysis}

All reports were reviewed independently by two authors $(\mathrm{CD} / \mathrm{SA})$ and differences were reconciled by mutual agreement. We systematically extracted data regarding (a) the described signs, (b) the setting of the study, (c) the objectives and outcome measures, (d) the study design, (e) the symptoms and case definitions of the patients and (f) the year of the study.

For the sake of uniformity, we chose to use the term 'functional' when reporting about patients, even when the authors themselves used another terminology (ie, hysterical, pithiatic, psychogenic, conversion, medically unexplained). We extracted the number of positive and negative signs in organic and functional groups in order to calculate the specificity and sensitivity of each sign. When several studies were found on the same sign, we pooled the data and the estimated pooled sensitivity and specificity are reported in table 1 , along with the positive predictive value and negative predictive value of each sign.

\section{RESULTS}

Our search criteria identified 215 articles but 68 of them were not relevant to the topic of CD. Of the remaining 147 articles, 88 were either case reports or studies with less than 10 participants. After careful reading of the full-length articles of the remaining 59 studies, we identified 11 studies fulfilling our inclusion criteria. Details of those 11 studies are presented in table 1.

\section{Analysis}

Ten studies reported data on 23 or less functional patients and only one case-control study focused on a bigger cohort of 107 patients. A total of 251 functional patients were examined. Six studies reported positive signs in functional weakness, one in sensory disturbances, one in gait disorders and three in combined symptoms. Six studies defined their primary outcome as to determine the frequency of a specific $\operatorname{sign}^{13-18}$ and thus provided reliable sensitivity and specificity estimates. Two studies focused on objective equivalents of clinical signs: Hoover ${ }^{19}$ and give-way weakness. ${ }^{19} 20$ Three studies compared clinical characteristics of functional and organic patients in case-control designs. $^{21-23}$ Two studies using objective quantification methods were judged Class II and nine studies using clinical bedside tests were judged class III, none reported inter-rater reliability of the signs. Altogether, those studies reported information on 14 clinical signs (7 motor, 5 sensory, 2 gait), most of them in single studies, with the exception of the Hoover sign (4 studies). A detailed description of those signs is presented here (see also table 1 ).

\section{Motor signs}

The Hoover's sign is based on the assumption that when a limb does a flexion, the contralateral limb does a reflex simultaneous extension movement. It is considered positive when there is weakness of voluntary hip extension in the presence of normal involuntary hip extension during contralateral hip flexion against resistance. Our systematic search identified four studies reporting the frequency of this sign. The sensitivity varied between $100 \%,{ }^{15} 95 \%,{ }^{21} 75 \%{ }^{14}$ and $63 \%{ }^{13}$ and specificity between $100 \%{ }^{13-15}$ and $86 \% .^{21}$ The first three studies were not primarily designed to evaluate the Hoover's sign; only a subset of subjects (59\% of patients and $16 \%$ of controls $\mathrm{in}^{21}$ ) presented leg weakness sufficient to render the Hoover's sign applicable. Only the study of McWhirter et al was designed to prospectively evaluate this sign. Pooling the data of those four studies when Hoover's sign was evaluable (148 controls and 92 patients) the overall estimated sensitivity is $94 \%$ and the specificity $99 \%$.

To obtain an objective equivalent of this test, a computerised quantitative version of the manoeuvre has been evaluated ${ }^{19}$ in nine functional and seven organic patients. It showed a significant increase in the involuntary/voluntary strength ratio in functional patients compared with organic patients, who had a ratio similar to healthy volunteers (see online supplementary table).

The abductor sign is based on the same principle as the Hoover's sign, assuming a reflex contralateral movement and has been evaluated in a single study on 17 organic and 16 functional unilateral lower limb paresis. ${ }^{14}$ The test yielded $100 \%$ sensitivity and $100 \%$ specificity, but an unblinded design was used and no information is provided on inter-rater reliability of the sign.

The abduction finger $\operatorname{sign} n^{15}$ is again based on the same principle: the fifth finger of the affected hand will display a synkinetic abduction when testing the abduction of fingers in the healthy hand. This sign was evaluated by an examiner blinded to the diagnosis in 36 healthy controls, 10 functional patients and 11 organic patients. It was present in all healthy subjects and all functional patients but in none of the organic patients, yielding a $100 \%$ sensitivity and $100 \%$ specificity. However, this study did not control for the degree of paresis and a bias towards more severe paresis in organic patients could have prevented the abduction from being seen. Therefore this test is only applicable when a complete hand plegia is present.

The Spinal Injuries Center test has been evaluated in 14 patients with functional leg paresis and 48 organic controls. Legs are passively positioned in a flexed posture in patients lying in bed. When the paretic leg falls, the test is considered negative, whereas when the paretic leg stays in a flexed posture, it is considered positive. It showed high sensitivity (100\%) and specificity (97.9\%); but the evaluation was not blinded and its use was limited to patients with severe paralysis who could not lift up their knees.

Collapsing weakness or give-away weakness is a commonly accepted sign for functional paresis. It demonstrates that patients are able to produce a reasonable strength, but when tested against the examiner's resistance, the power quickly 'gives 
Table 1 Positive signs of functional motor, sensory and gait disorders

\begin{tabular}{|c|c|c|c|c|c|c|c|}
\hline Clinical sign & $\begin{array}{l}\text { Estimated } \\
\text { specificity (CI) }\end{array}$ & $\begin{array}{l}\text { Estimated } \\
\text { sensitivity }(\mathrm{Cl})\end{array}$ & $\begin{array}{l}\text { Positive predictive } \\
\text { value }(\mathrm{Cl})\end{array}$ & $\begin{array}{l}\text { Negative predictive } \\
\text { value }(\mathrm{Cl})\end{array}$ & Description & Comment & References \\
\hline \multicolumn{8}{|l|}{ Motor } \\
\hline \multicolumn{8}{|l|}{ Validated } \\
\hline Hoover sign & $99 \%$ (95.7 to 99.9 ) & $94 \%$ (85.8 to 97.3 ) & $99 \%$ (92.8 to 99.9 ) & $96 \%$ (91.3 to 98.4$)$ & $\begin{array}{l}\text { A:P supine, E hand under paretic leg (under } \\
\text { heel): } P \text { exerts max force downward } \\
B: S a m e \text { but } P \text { exerts max force upward with } \\
\text { contralateral leg (against } E \text { resistance) } \\
\text { Comparison of felt pressure in E hand under } \\
\text { paretic side heel } \\
\text { Hoover+if strength in condition } B>A \\
\text { Hoover - if strength } B \geq A\end{array}$ & $\begin{array}{l}\text { Can only be applied when a } \\
\text { significant proximal leg weakness is } \\
\text { present. Caution when coexisting } \\
\text { comprehension/attention deficit or } \\
\text { cortical neglect or pain }\end{array}$ & $\begin{array}{l}\text { Stone et al }{ }^{21}, \\
\text { Sonoo }{ }^{14}, \\
\text { Tinazzi et al }{ }^{15}, \\
\text { McWhirter et } a l^{13}, \\
\text { Ziv et al }{ }^{19}\end{array}$ \\
\hline Abductor sign & $100 \%(77.1$ to 100$)$ & $100 \%(75.9$ to 100$)$ & $100 \%(75.9$ to 100$)$ & $100 \%(77.1$ to 100$)$ & $\begin{array}{l}\text { A:P supine, E hands on both sides, P exerts full } \\
\text { abduction with both legs (paretic legs stays on } \\
\text { midline) } \\
\text { B:P exerts max strength on abducted leg } \\
\text { (against E resistance) } \\
\text { Sign-if paretic leg moves in adduction } \\
\text { Sign+if paretic leg stays in position }\end{array}$ & $\begin{array}{l}\text { Rather complex manoeuvre with no } \\
\text { data on inter-rater reliability }\end{array}$ & Sonoo $^{14}$ \\
\hline Abductor finger sign & $100 \%(67.9$ to 100$)$ & $100 \%(65.5$ to 100$)$ & $100 \%(65.5$ to 100$)$ & $100 \%(67.8$ to 100$)$ & $\begin{array}{l}\text { P abduction finger movement against resistance } \\
\text { of } \mathrm{E} \text { for } 2 \text { min with healthy hand. Synkinetic } \\
\text { abduction finger movements of contralateral/ } \\
\text { 'paretic' hand in functional paresis, no } \\
\text { movement in 'organic' paresis }\end{array}$ & $\begin{array}{l}\text { Can only be applied to patients with } \\
\text { moderate paresis }\end{array}$ & Tinazzi et al $\left.\right|^{15}$ \\
\hline Spinal injury test & $98 \%$ (87.5 to 99.9 ) & $100 \%(73.2$ to 100$)$ & $93 \%$ (66.0 to 99.7$)$ & $100 \%(90.6$ to 100$)$ & $\begin{array}{l}\text { P supine position asked to lift up his knees, if } \\
\text { not possible E lift them up } \\
\text { Sign+if P keeps them up, sign-if leg drop in } \\
\text { abduction }\end{array}$ & $\begin{array}{l}\text { Can only be applied when a } \\
\text { significant proximal leg weakness is } \\
\text { present }\end{array}$ & Yugue et $a l^{18}$ \\
\hline $\begin{array}{l}\text { Collapsing/give-away } \\
\text { weakness }\end{array}$ & $97 \%$ (89.4 to 99.1$)$ & $63 \%$ (53.9 to 71.5 ) & $96 \%$ (88.7 to 99 ) & $65 \%$ (55.9 to 72.9 ) & $\begin{array}{l}\text { Limb collapses from a normal position with a } \\
\text { light touch or a normal strength is developed } \\
\text { and then suddenly collapses (or gives-way) }\end{array}$ & $\begin{array}{l}\text { Prone to error in patients with pain } \\
\text { or who have difficulty following } \\
\text { instructions }\end{array}$ & $\begin{array}{l}\text { Stone et al }{ }^{21} \\
\text { Chabrol et }\left.a\right|^{22} \\
\text { Gould et } a l^{8}\end{array}$ \\
\hline Co-contraction & $100 \%(82.2$ to 100$)$ & $17 \%$ (5.7 to 39.5 ) & $100 \%(39.6$ to 100$)$ & $55 \%$ (38.8 to 69.8 ) & $\begin{array}{l}\text { Observation during muscle strength testing (or } \\
\text { with surface electromyogram) } \\
\text { Sign+if simultaneous contraction of agonist and } \\
\text { antagonist resulting in no/little movement }\end{array}$ & $\begin{array}{l}\text { Excessive antagonist activation can } \\
\text { also be observed in spastic patients }\end{array}$ & $\begin{array}{l}\text { Baker \& Silver }{ }^{23} \\
\text { Knutsson } 1985^{23 a}\end{array}$ \\
\hline Motor inconsistency & $98 \%$ (85.3 to 99.9 ) & $13 \%$ (2.3 to 41.6$)$ & $67 \%$ (12.5 to 98.2$)$ & $75 \%$ (60.7 to 85.5$)$ & $\begin{array}{l}\text { Impossibility to do a movement while another } \\
\text { movement using the same muscle is possible }\end{array}$ & $\begin{array}{l}\text { Easy to detect but needs careful } \\
\text { observation during the entire } \\
\text { examination. Only formally evaluated } \\
\text { in a single study }\end{array}$ & Chabrol et al ${ }^{22}$ \\
\hline \multicolumn{8}{|l|}{ Not validated } \\
\hline $\begin{array}{l}\text { Non-pyramidal } \\
\text { weakness }\end{array}$ & & & & & $\begin{array}{l}\text { Weakness is equally distributed in all muscle } \\
\text { groups in functional cases } \\
\text { Weakness is predominant in flexors>extensors } \\
\text { and distal>proximal in pyramidal cases }\end{array}$ & $\begin{array}{l}\text { Can only be used to differentiate } \\
\text { with a central lesion and not a } \\
\text { peripheral lesion }\end{array}$ & $\begin{array}{l}\text { Freud }^{3}, \text { Koehler } \\
2004^{23 \mathrm{~b}}\end{array}$ \\
\hline Absent pronator drift & & & & & $\begin{array}{l}\text { During the arm stabilisation test, hands in a } \\
\text { supinated position: } \\
\text { A downward drift and/or pronation is seen in } \\
\text { organic but not in psychogenic paresis }\end{array}$ & $\begin{array}{l}\text { Expert opinion } \\
\text { Studies showing high specificity of } \\
\text { this sign for organic paresis, but has } \\
\text { never been tested in functional } \\
\text { paresis }\end{array}$ & $\begin{array}{l}\text { Babinski42 } \\
\text { Teitelbaum et } a^{35} \\
\text { Anderson et } a^{36}\end{array}$ \\
\hline
\end{tabular}


Table 1 Continued

\begin{tabular}{|c|c|c|c|c|c|c|c|}
\hline Clinical sign & $\begin{array}{l}\text { Estimated } \\
\text { specificity (CI) }\end{array}$ & $\begin{array}{l}\text { Estimated } \\
\text { sensitivity (CI) }\end{array}$ & $\begin{array}{l}\text { Positive predictive } \\
\text { value (Cl) }\end{array}$ & $\begin{array}{l}\text { Negative predictive } \\
\text { value }(\mathrm{Cl})\end{array}$ & Description & Comment & References \\
\hline Arm drop test & & & & & $\begin{array}{l}\text { E puts P's arm over the head (P lying supine) } \\
\text { and drops the weak arm: } \\
\text { In organic paresis the arm hits the face } \\
\text { In functional paresis a voluntary movement } \\
\text { allows avoiding the face }\end{array}$ & $\begin{array}{l}\text { Only anecdotally reported } \\
\text { Can only be applied in cases of } \\
\text { complete paralysis of the arm }\end{array}$ & $\begin{array}{l}\text { Reeves and } \\
\text { Bullen } n^{40} \text {, Greer } \\
\text { et } a^{39} \text {, Marcus } \\
\text { et } a^{\beta^{38}}\end{array}$ \\
\hline $\begin{array}{l}\text { Barré test ('manoeuvre } \\
\text { de la jambe') }\end{array}$ & & & & & $\begin{array}{l}\text { P in prone position legs bent at } 90^{\circ} \text { : } \\
\text { In organic paresis, leg falls but contraction of } \\
\text { hamstring muscle is seen } \\
\text { In functional paresis, leg falls without } \\
\text { contraction of the hamstrings } O R \text { no fall at all }\end{array}$ & Expert opinion & Barré $^{41}$ \\
\hline $\begin{array}{l}\text { Wrong way tongue } \\
\text { deviation }\end{array}$ & & & & & $\begin{array}{l}\text { In organic hemiparesis a slight tongue deviation } \\
\text { towards the paresis can be seen. In functional } \\
\text { paresis a strong deviation can occur, usually } \\
\text { away from the paresis } \\
\text { Sign+if tongue deviation away from the } \\
\text { hemiparesis }\end{array}$ & Only one uncontrolled study & Keane $^{49}$ \\
\hline $\begin{array}{l}\text { Platysma sign ('signe } \\
\text { du peaucier') }\end{array}$ & & & & & $\begin{array}{l}P \text { is asked to open wide the mouth and/or to } \\
\text { flex the chin towards the chest against } E \\
\text { resistance } \\
\text { In organic paresis a weakness is seen on the } \\
\text { paretic side } \\
\text { In functional paresis no asymmetry is seen }\end{array}$ & Expert opinion & Babinski $^{42}$ \\
\hline $\begin{array}{l}\text { Babinski trunk-thigh } \\
\text { test }\end{array}$ & & & & & $\begin{array}{l}\text { P supine position, arms across chest, asked to } \\
\text { sit up } \\
\text { In organic paresis, the paretic limb raises above } \\
\text { the bed and the contralateral shoulder comes } \\
\text { forward } \\
\text { In functional paresis, no asymmetry is seen }\end{array}$ & Expert opinion & Babinski $^{42}$ \\
\hline Supine catch sign & & & & & $\begin{array}{l}\mathrm{P} \text { is asked to put the hand in supination } \\
\text { In organic paresis, the wrist joint stays in } \\
\text { neutral position and fingers flex } \\
\text { In functional paresis, the wrist hyper extends } \\
\text { and fingers extend }\end{array}$ & $\begin{array}{l}\text { Case report, only useful in cases of } \\
\text { wrist drop (radial nerve palsy or hand } \\
\text { knob cortical lesion) }\end{array}$ & Sethi et al ${ }^{44}$ \\
\hline Sternocleidomastoid test & & & & & $\begin{array}{l}\text { Test the SCM strength by asking P to do a } \\
\text { forced head rotation against E resistance. In } \\
\text { organic hemiparesis SCM usually spared (as } \\
\text { bilateral innervations). Sign+if weakness of } \\
\text { rotation to the ipsilateral side }\end{array}$ & $\begin{array}{l}\text { Controlled study but data only } \\
\text { obtained on an abstract, article in } \\
\text { Russian }\end{array}$ & $\begin{array}{l}\text { Diukova }^{45} \text {, Diukova } \\
\text { and Stoliarova }\end{array}$ \\
\hline \multicolumn{8}{|l|}{ Sensory } \\
\hline \multicolumn{8}{|l|}{ Validated } \\
\hline Midline splitting & $93 \%$ (83.8 to 96.9$)$ & $20 \%$ (6.6 to 44.2$)$ & $40 \%(13.6$ to 72,6$)$ & $82 \%$ (72.4 to 89.2$)$ & $\begin{array}{l}\text { Sign+if exact splitting of sensation in the } \\
\text { midline }\end{array}$ & $\begin{array}{l}\text { The differential diagnosis includes } \\
\text { small thalamic lesions }\end{array}$ & $\begin{array}{l}\text { Rolak }^{16} \text {, Stone } \\
\text { et } a l^{21} \text {, } \\
\text { Chabrol et all } \\
\text { Gould et } a l^{8}\end{array}$ \\
\hline Splitting of vibration & $14 \%(7.3$ to 23.7$)$ & $95 \%$ (73.1 to 99.7 ) & $22 \%$ (13.8 to 31.9$)$ & $92 \%$ (59.8 to 99.5 ) & $\begin{array}{l}\text { Sign+if difference in the sensation of a tuning } \\
\text { fork placed over the left compared to the right } \\
\text { side of the sternum or frontal bone }\end{array}$ & $\begin{array}{l}\text { A low specificity is reported from a } \\
\text { single study. The assessment did not } \\
\text { measure the degree of reported } \\
\text { asymmetry }\end{array}$ & $\begin{array}{l}\text { Rolak }^{16} \text {, } \text { Gould et al }^{8} \text {, } \\
\text { Toth }^{26}\end{array}$ \\
\hline
\end{tabular}


Table 1 Continued

\begin{tabular}{|c|c|c|c|c|c|c|c|}
\hline Clinical sign & $\begin{array}{l}\text { Estimated } \\
\text { specificity (Cl) }\end{array}$ & $\begin{array}{l}\text { Estimated } \\
\text { sensitivity (Cl) }\end{array}$ & $\begin{array}{l}\text { Positive predictive } \\
\text { value }(\mathrm{Cl})\end{array}$ & $\begin{array}{l}\text { Negative predictive } \\
\text { value }(\mathrm{Cl})\end{array}$ & Description & Comment & References \\
\hline $\begin{array}{l}\text { Non anatomical } \\
\text { sensory loss }\end{array}$ & $100 \%(82.2$ to 100$)$ & $74 \%(51.3$ to 88.9$)$ & $100 \%(77.1$ to 100$)$ & $79 \%$ (59.7 to 91.3 ) & $\begin{array}{l}\text { Diminished sensation fitting a 'non-dermatomal } \\
\text { pattern' for example: anteriorly but not } \\
\text { posteriorly delineated truncal deficit, unilateral } \\
\text { glove or sock distribution, sharp midline } \\
\text { delineation in one limb (hemilimb distribution) }\end{array}$ & $\begin{array}{l}\text { Evaluated in a single study with no } \\
\text { precise description of what was } \\
\text { considered 'non-anatomical' }\end{array}$ & Baker \& Silver ${ }^{23}$ \\
\hline $\begin{array}{l}\text { Inconsistency/Changing } \\
\text { pattern of sensory loss }\end{array}$ & $70 \%$ (56.8 to 80.4 ) & $79 \%(62.2$ to 89.9$)$ & $61 \%$ (46.2 to 74.5$)$ & $85 \%$ (71.4 to 92.7$)$ & $\begin{array}{l}\text { Inconsistency and non reproducibility of sensory } \\
\text { signs in repeated sensory testing }\end{array}$ & $\begin{array}{l}\text { No precise description on how to } \\
\text { perform the repeated tests }\end{array}$ & $\begin{array}{l}\text { Baker \& Silver } 23 \\
\text { Chabrol et } a^{22}\end{array}$ \\
\hline Systematic failure & $100 \%(82.2$ to 100$)$ & $8.7 \%$ (1.5 to 29.5$)$ & $100 \%(19.8$ to 100$)$ & $100 \%$ (36.9 to 67.3$)$ & $\begin{array}{l}\text { Sign+if patients always fails in a discriminative } \\
\text { task (eg, pin or prick/cold-hot/upgoing or } \\
\text { downgoing joint) }\end{array}$ & $\begin{array}{l}\text { Evaluated in a single study but no } \\
\text { precise description given on how } \\
\text { many times the task should be } \\
\text { repeated }\end{array}$ & Baker \& Silver ${ }^{23}$ \\
\hline \multicolumn{8}{|l|}{ Not validated } \\
\hline Bowlus-Currier test & & & & & $\begin{array}{l}P \text { is asked to place palms together, thumbs } \\
\text { down (wrist crossed), fingers interlocked and } \\
\text { then rotate hands to bring them in front of the } \\
\text { chest } \\
\text { E performs sensory testing, starting on fifth } \\
\text { finger up to the thumb (which is the only } \\
\text { uncrossed finger) } \\
\text { In functional paresis P reports that the healthy } \\
\text { thumb is anaesthetic }\end{array}$ & $\begin{array}{l}\text { Evaluated in a single study. Implies } \\
\text { some 'doctor trickery' and should be } \\
\text { used with caution }\end{array}$ & $\begin{array}{l}\text { Bowlus and } \\
\text { Currier }^{48}\end{array}$ \\
\hline Yes/no test & & & & & $\begin{array}{l}\text { P, eyes closed, is asked to 'yes' when he feels E } \\
\text { touching and 'no' when he does not }\end{array}$ & $\begin{array}{l}\text { Implies some 'doctor trickery' and } \\
\text { should be used with caution }\end{array}$ & $\begin{array}{l}\text { Stone et } a^{21} \\
\text { Magee }^{25}\end{array}$ \\
\hline \multicolumn{8}{|l|}{ Gait } \\
\hline \multicolumn{8}{|l|}{ Validated } \\
\hline $\begin{array}{l}\text { Dragging monoplegic } \\
\text { gait }\end{array}$ & $100 \%(90.4$ to 100$)$ & $8.4 \%$ (4.2 to 15.8$)$ & $100 \%(62.9$ to 100$)$ & $32 \%$ (24.6 to 40.3 ) & $\begin{array}{l}\text { The leg is dragged at the hip behind the body } \\
\text { instead of performing a circumduction }\end{array}$ & $\begin{array}{l}\text { Data available in a case-control } \\
\text { study, as well as in two } \\
\text { observational series }\end{array}$ & $\begin{array}{l}\text { Stone et al }{ }^{21} \\
\text { Keane }^{49}, \\
\text { and Whrbar } \\
\text { Waespe }\end{array}$ \\
\hline Chair test & $100 \%(62.8$ to 100$)$ & $89 \%$ (50.7 to 99.4 ) & $100 \%$ (59.7 to 100$)$ & $90 \%$ (54.1 to 99.4 ) & $\begin{array}{l}\text { Sign+when } \mathrm{P} \text { is seen to propel a swivel chair } \\
\text { better than walking }\end{array}$ & $\begin{array}{l}\text { Evaluated in a single study. Complex } \\
\text { testing with no estimation of } \\
\text { inter-rater reliability }\end{array}$ & Okun et $a l^{17}$ \\
\hline \multicolumn{8}{|l|}{ Not validated } \\
\hline Fluctuation & & & & & $\begin{array}{l}\text { Variability of gait with periods of normal gait } \\
\text { are observed }\end{array}$ & $\begin{array}{l}\text { Also possible in neurological disease } \\
\text { (eg, myasthenia gravis) }\end{array}$ & $\begin{array}{l}\text { Lempert et a }{ }^{51} \\
\text { Okun et al }\end{array}$ \\
\hline Excessive slowness & & & & & $\begin{array}{l}\text { Excessive slowness or hesitation incompatible } \\
\text { with a neurological disease is observed }\end{array}$ & $\begin{array}{l}\text { Orthopaedics patients can walk } \\
\text { slowly to avoid pain }\end{array}$ & $\begin{array}{l}\text { Baik and Lang }{ }^{53}, \\
\text { Lempert et } a l^{51} \text {, } \\
\text { Okun et } a l^{17}\end{array}$ \\
\hline Psychogenic Romberg & & & & & $\begin{array}{l}\text { Constant falls towards or away from the } \\
\text { observer, large amplitude body sway building } \\
\text { up after a silent latency of a few seconds and } \\
\text { improvement of balance with distraction }\end{array}$ & Evidence from a single study & Lempert et al ${ }^{51}$ \\
\hline Walking on ice & & & & & $\begin{array}{l}\text { A walking pattern mimicking ice skating or 'as } \\
\text { if' on slippery grounds }\end{array}$ & Evidence from a single study & Lempert et $\left.a\right|^{51}$ \\
\hline Non-economic posture & & & & & $\begin{array}{l}\text { A walking pattern that requires considerable } \\
\text { effort as well as balance to maintain the } \\
\text { posture (eg, walking with knees flexed) }\end{array}$ & $\begin{array}{l}\text { Evidence from two studies, only } \\
\text { providing descriptions }\end{array}$ & $\begin{array}{l}\text { Lempert et } a l^{51} \text {, } \\
\text { Okun et } a l^{17}\end{array}$ \\
\hline
\end{tabular}


Table 1 Continued

\begin{tabular}{|c|c|c|c|c|c|c|c|}
\hline Clinical sign & $\begin{array}{l}\text { Estimated } \\
\text { specificity (CI) }\end{array}$ & $\begin{array}{l}\text { Estimated } \\
\text { sensitivity (Cl) }\end{array}$ & $\begin{array}{l}\text { Positive predictive } \\
\text { value }(\mathrm{Cl})\end{array}$ & $\begin{array}{l}\text { Negative predictive } \\
\text { value }(\mathrm{Cl})\end{array}$ & Description & Comment & References \\
\hline Sudden knee buckling & & & & & $\begin{array}{l}\text { Knee buckling during stance or walk but usually } \\
\text { with no falls }\end{array}$ & Can be seen in chorea & $\begin{array}{l}\text { Keane } e^{49} \text {, Baik and } \\
\text { Lang }{ }^{53} \text {, Lempert } \\
\text { et } \mathrm{a}^{51} \text {, Okun } \\
\text { et } \mathrm{a} \mathrm{l}^{17}\end{array}$ \\
\hline $\begin{array}{l}\text { Staggering long to } \\
\text { obtain support from } \\
\text { opposite walls }\end{array}$ & & & & & $\begin{array}{l}\text { Very instable gait but no falls, as subject will } \\
\text { find a support, even if far out of reach }\end{array}$ & Evidence from a single study & Keane $^{49}$ \\
\hline $\begin{array}{l}\text { Exaggerated swaying } \\
\text { without falling }\end{array}$ & & & & & Similar to the 'psychogenic' Romberg above & Evidence from a single study & Keane $^{49}$ \\
\hline Astasia-abasia & & & & & $\begin{array}{l}\text { Complete inability to stand and walk despite } \\
\text { normal leg function in bed }\end{array}$ & $\begin{array}{l}\text { Thalamic lesions can cause an } \\
\text { inability to stand (thalamic astasia) }\end{array}$ & $\begin{array}{l}\text { Blocq }^{29}, \text { Knapp }^{49 a} \text {, } \\
\text { Baik } 2007 . \\
\text { Lempert et al }{ }^{51}\end{array}$ \\
\hline $\begin{array}{l}\text { Opposite of } \\
\text { astasia-abasia }\end{array}$ & & & & & $\begin{array}{l}\text { Complete inability to move legs in bed despite } \\
\text { intact walking pattern }\end{array}$ & $\begin{array}{l}\text { Reported in } 23 / 47 \text { patients in a } \\
\text { single uncontrolled study }\end{array}$ & $\begin{array}{l}\text { Ehrbar and } \\
\text { Waespe }\end{array}$ \\
\hline Sudden side steps & & & & & $\begin{array}{l}\text { Functional patients will display big displacement } \\
\text { in their trajectory with sudden side steps, } \\
\text { without falling }\end{array}$ & $\begin{array}{l}\text { Cerebellar ataxia (vermis) can also } \\
\text { induce sudden side steps }\end{array}$ & $\begin{array}{l}\text { Diukova Diukova } \\
\text { and Stoliarova }{ }^{52}\end{array}$ \\
\hline Cross legs & & & & & $\begin{array}{l}\text { Patients will display a crossed legs or scissoring } \\
\text { pattern of walk }\end{array}$ & Described in two studies & $\begin{array}{l}\text { Diukova Diukova } \\
\text { and Stoliarova }{ }^{52} \\
\text { Keane }^{49}\end{array}$ \\
\hline Expressive behaviour & & & & & $\begin{array}{l}\text { 'Suffering and strained facial expression', } \\
\text { mannered posture of the hand, moaning, } \\
\text { hyperventilation }\end{array}$ & $\begin{array}{l}\text { Patients with severe pain can display } \\
\text { such behaviours }\end{array}$ & Lempert et al ${ }^{51}$ \\
\hline
\end{tabular}

E, examiner, P, patient; SCM, Sternocleidomastoid. 
away'. Two studies report collapsing weakness in functional patients with low sensitivity of $20 \%{ }^{22}$ and $70 \%{ }^{21}$ but a high specificity of $95 \%$ and $98 \%$, respectively. When pooling the data on 122 functional patients and 86 controls, the estimated sensitivity was $63 \%$ and the specificity $97 \%$. Like the Hoover sign, this test relies on the examiner's subjective interpretation of strength. However, electrophysiological evaluations using dynamometer measurements have supported evidence ${ }^{20}$ for this clinical sign by obtaining an objective equivalent; the 'break index'. This index was shown to be significantly higher in functional compared with organic weakness. The authors further validated it in a cohort of 20 subjects in a blinded protocol, and found $100 \%$ sensitivity and $89 \%$ specificity. This index is interesting, although not applicable to bedside testing, as it quantitatively measures what clinicians commonly consider give-way weakness.

The co-contraction sign, defined as the simultaneous contraction of an antagonist muscle when voluntarily contracting an agonist, was studied in 20 functional paraplegic patients compared with 23 organic patients ${ }^{23}$ and showed a low sensitivity of $17 \%$ but a high specificity of $100 \%$.

Motor performance variability or inconsistency is another classical sign characterised by discordance in motor testing between two given situations: a patient with complete plegia of a limb when tested in a supine position stands on the previously plegic limb and walks out of the examination room. Only one study reports data on this sign, referred to as the impossibility to do a movement while another movement using the same muscle is possible, ${ }^{22}$ in 2/15(12\%) functional patients and 1/40 (2.5\%) organic controls, inferring a sensitivity of $13 \%$ but a specificity of $98 \%$.

\section{Sensory signs}

Midline splitting of sensory deficit is defined by a sensory loss of half of the body (with face, trunk, arm and leg involvement) with a clear edge on the midline. It has been interpreted as a functional sign, as anatomical central lesions usually spare the trunk. Thalamic lesions (lacunar stroke or tumours) are thought to be the only alternate explanation. A pattern of midline splitting has been reported in 4/15(27\%) functional patients and in 6/40 (15\%) neurological controls ${ }^{22}$ yielding low sensitivity of $26 \%$ but high specificity of $85 \%$. Another case-control study reported a midline splitting in 20/107(19\%) functional weakness subjects but in only $1 / 46(2 \%)$ neurological controls ${ }^{21}$ yielding a sensitivity of $18 \%$ but a high specificity of $98 \%$. Both studies included mixed motor and sensory symptoms but the main focus of the study was not to test for sensory deficits. The only controlled study ${ }^{16}$ specifically looking at sensory deficit reported similar low sensitivity (20\%) and high specificity (93\%).

Splitting of vibration sense has been suggested as a sign of functional sensory loss, as vibration is perceived mainly through bone conduction. Placing a tuning fork on the right or left side of the forehead or the sternum is thus expected to be felt identically, as the same bone is involved. This sign was evaluated in a sample of 100 consecutive subjects complaining of facial unilateral numbness, $80 \%$ of which were organic and $20 \%$ were functional. ${ }^{16}$ A tuning fork was placed on the forehead of the normal side first and subjects were asked to compare the feeling of both sides: $19 / 20(95 \%)$ of the functional patients reported a diminished vibration on the numb side but so did $69 / 80$ (86\%) of the organic patients. This study suggests that although sensitive (95\%) this sign has a very low specificity (14\%). The study was not blinded, the method did not ensure that both sides receive exactly the same vibration and the degree of diminished sensation was not assessed. Such diminished vibration sensation on the numb side has been found in 39\% functional cases and 11\% organic controls, but it is important to highlight that the opposite (ie, increased vibration sensation on the numb side) was also present in $7 \%$ of functional cases and $7 \%$ of organic controls. ${ }^{21}$

Non-anatomical sensory loss ${ }^{23}$ showed a $69.6 \%$ sensitivity and $100 \%$ specificity in 20 functional paraplegic subjects compared with 23 organic controls. However, no precise description of what was considered 'non-anatomical' is provided. Classically, truncal deficits that have only an anterior level but not posterior level, sharply demarcated boundaries at the shoulder or at the groin, a shape of strictly unilateral glove or sock or involvement of only half a limb are considered non-anatomical. ${ }^{24-26}$

Inconsistency and non-reproducibility of sensory signs were found $^{23}$ in 23/23 functional patients and in none of the 23 organic patients, yielding a $100 \%$ sensitivity and $100 \%$ specificity. Much lower sensitivity (46\%) and specificity (52.5\%) were reported in another study looking at a changing pattern of sensory loss. ${ }^{22}$ When pooling the data on those 38 functional patients and 63 organic controls, this sign shows a sensitivity of $79 \%$ and specificity of $70 \%$. Better definitions of this sensory variability are needed before it can be interpreted as specific for functional disorders, as parietal lesions are also known to produce inconsistencies in sensory testing. ${ }^{25} 27$

The sign of systematic failure where patients perform poorer than chance on a discrimination task, like upward/downward joint displacement has been tested in a single study ${ }^{23}$ showing low sensitivity $(8,6 \%)$ but very high specificity (100\%).

\section{Abnormal gait signs}

In pyramidal leg weakness, a pattern of circumduction is expected. In his renowned clinical lectures, Todd described that hysterical patients did not display this circumduction pattern but had a characteristic way to drag their leg after them 'as if it was an inanimate matter'. ${ }^{28}$ Such a dragging monoplegic gait has been found in $9 \%$ of functional cases (107) but in none of 46 organic controls in a case-control study design, inferring a low sensitivity of $8 \%$ but very high specificity of $100 \%$.

The chair test $^{17}$ is based on Blocq's description ${ }^{29}$ of patients suffering from non-organic astasia-abasia (inability to stand or walk despite normal function in bed), who were observed to perform well in propelling a chair. Eight out of nine functional patients showed a better performance when propelling a swivel chair than when walking, when none of the nine organic patients (seven with Parkinson's disease, two with multiple system atrophy) did. The 'chair test' showed a sensitivity of $88.9 \%$ and specificity of $100 \%$.

\section{DISCUSSION FOR THE SYSTEMATIC REVIEW}

Our systematic search found only 11 articles providing data on the validation of 14 clinical signs in functional weakness, sensory and gait disorders. Nine class III studies were found, only two prospective blinded studies are available and no data exists regarding the inter-rater reliability of those positive clinical signs. This is striking, as it is still expected in DSM and International Classification of Diseases (ICD) classifications that the diagnosis of $\mathrm{CD}$ is made on clinical grounds. At present no guidelines ensure that clinicians have the same standard across the world. Providing clinicians rely on the 14 signs evaluated in this systematic study, one can however expect the diagnosis of functional disorder to be accurate as most of those signs showed a good specificity ranging from $93-100 \%$, with the exception of splitting of vibration (14\%). The estimated positive predictive values (PPVs) showed greater variability from $20-100 \%$ but PPVs are dependent on the prevalence of the disease in the tested population. In the present review, PPVs are derived from heterogeneous 
populations extracted from different studies. Therefore more emphasis should be put on the specificity values, until better designed, population-based studies can provide reliable PPVs for each clinical sign. To date the most valid sign is the Hoover sign with an estimated overall sensitivity of $94 \%$ and specificity of $99 \%$. It is interesting to note that its equivalent for the upper limbs might be available, as it has been tested in an objective quantification of strength using a dynamometer. ${ }^{19}$ A clinical validation of its bedside use should be done. The abductor sign, the abductor finger sign and the spinal injury sign are highly specific motor signs that can be extremely useful, even though replication studies are warranted. More widely used classical signs, such as inconsistency, give-way and co-contraction have also shown good specificity between (98-100\%). Less sensory signs are available but here again classical signs such as inconsistency and nonanatomical pattern are highly specific (100\%). Regarding gait signs, only two had some validity: dragging monoplegic leg and the chair sign. The latter having been compared mainly to parkinsonian controls still needs to be adequately assessed on patients with other pathologies.

In summary, few signs have been validated but data extracted here show that the currently available 'positive' signs for functional disorder are highly specific. It is thus important to highlight the fact that CD (functional symptom disorder) is not a diagnosis of exclusion but has specific features that allow a positive diagnosis. This is important, as patients and their treating physicians need reassurance that $\mathrm{CD}$ is a reliable diagnosis. In general, doctors find functional patients difficult to handle ${ }^{30}$ and the fear of missing an organic cause ${ }^{31}$ has been prominent, until recent evidence was gathered to prove low misdiagnosis rates. ${ }^{32}$ However, more validation of those signs is warranted along with teaching and spreading of their use in order to ensure that the same diagnostic standards are met in clinical and research settings in the future.

\section{LIMITATIONS}

The conclusions of this review must be qualified by the limitations inherent in the studies that it included. As no gold standard exists for functional weakness, sensory and gait disturbances, precise diagnostic criteria on how a diagnosis of functional disorder has been made are not always provided and wrong attribution of subjects could have occurred. More importantly and more likely, this could have introduced a circular reasoning bias (self-fulfilling prophecy): if the studied sign is also used in the diagnosis process, the reported specificity is overestimated. Also, a precise description of the clinical signs is not always provided. This could have introduced errors in the estimated sensitivity and specificity when pooling the data focussing on the same sign. Finally, for case-control studies not primarily intended to report data on clinical signs, we inferred frequencies from the published information and might have over-reported or under-reported some data.

\section{Narrative review}

Only 14 'positive' signs were found to have some degree of validation and are discussed in the systematic review, but many other clinical signs can be found embedded in case reports, small sample controlled studies or expert opinions. In this narrative part of our review, we provide information on those other relevant signs.

\section{Motor signs}

A 'non-pyramidal' distribution of paresis has been suggested in Sigmund Freud's account of hysterical paresis ${ }^{3}$ : An involvement of all muscle groups to an approximately equal degree would suggest hysteria, whereas in organic lesions the weakness is expected to be greater in the distal segment of the extremity than in the proximal one ${ }^{33}$ and involve flexor muscles to a greater extent than extensor muscles.

The absence of pronator drift in subjects with arm paresis has been described by Joseph Babinski as suggestive of hysteria. ${ }^{34}$ Indeed the pronation movement is a sign of upper motor neuron disorder. ${ }^{35} 36$ It is thus useful, during the arm stabilisation test with hands supinated, to carefully look when a downward drift occurs, if a concomitant pronation movement happens. When the hand is seen to go down but no pronation occurs, it is indicative of functional paresis. ${ }^{37}$

The arm drop test ${ }^{24} 3839$ or hand strike ${ }^{21}$ has been used to detect non-organic severe upper limb paresis. The limb is held over the patient's face and dropped by the examiner: in case of an organic paresis, the arm will drop on the subject's face, whereas in case of a functional paresis the patient will display a slight voluntary movement so that the arm avoids the face. This test is supported only anecdotally and even a case report ${ }^{40}$ questioned its validity as a patient who displayed this sign was found to have severe insulin-induced hypoglycaemia.

The Barré test ('manoeuvre de la jambe') described by Jean-Alexandre Barré ${ }^{41}$ has never been formally tested ever since its initial description: the patient lies in a ventral position and is instructed to keep his legs still after the examiner has put them in a flexed position at $90^{\circ} \mathrm{s}$. By doing so, the examiner discloses to the patient that this manoeuvre requires no or very little strength. In pyramidal weakness a downward extension movement of the leg will be seen, accompanied by contraction of the thigh muscles, proving the subject is trying to maintain the flexed position: this was considered a positive manoeuvre. In functional paresis, the leg is maintained in the flexed position, without downward extension movement or is seen to fall down straight away, without any thigh muscles contraction: this was considered a negative manoeuvre. The author tested his manoeuvre and found it to be positive in 33/36 organic pyramidal weaknesses and negative in 7/7 functional subjects.

Babinski $^{42}$ described that in cases of organic hemiparesis, when testing the tongue protrusion, one can observe a slight deviation towards the paresis, which is a sign of upper motor neuron disorder. In cases of functional hemiparesis, he noticed that the tongue is seen to have a very strong deviation, either towards the paralysis or away from it. To his view, this corresponded to what Charcot earlier described as a hysterical tongue spasm ('spasme glosso-labié unilateral'). ${ }^{42}$ In 1986, the wrong-way tongue deviation was observed in 4/22 hysterical subjects, ${ }^{43}$ where the tongue showed a strong deviation away from the hemiparesis with an impossibility to cross the midline. The authors of that study discuss that such a deviation away from the paretic side can be seen in anterior medullary lesions involving the ipsilateral 12th nerve nucleus and a contralateral paresis but that in organic cases the deviation is never that extreme and is rapidly accompanied by fasciculations.

The platysma sign ('signe du peaucier') ${ }^{42}$ is defined by an asymmetry of contraction (weaker on the side of the hemiparesis) seen in organic paresis when opening wide the mouth or when flexing the chin towards the chest against the examiner's pressure (figure 1). The careful observation of this sign could be helpful, as, according to Babinski, it was always absent in functional cases.

The Babinski trunk-thigh test ${ }^{42}$ is tested by asking a patient lying in a supine position to sit up, without the help of the arms that are kept crossed over the chest. In organic paresis, the weak leg is seen to flex at the hip and the heel to rise above the bed, 


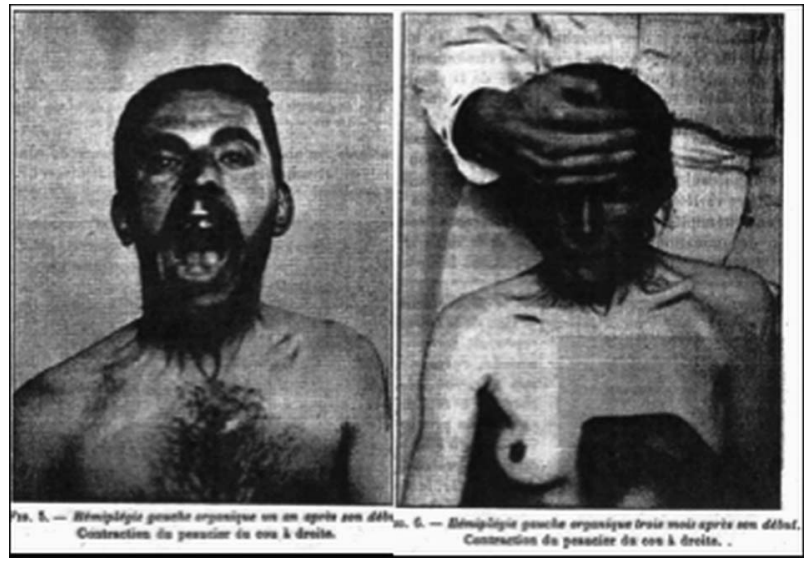

Figure 1 Platysma sign. From Babinski. ${ }^{42}$

while the healthy shoulder makes a forward movement (see figure 2). In functional paresis, the patients either cannot sit at all or will sit with symmetrical leg movements.

The supine catch $\operatorname{sign}{ }^{44}$ has been reported in a case of functional wrist drop. In organic peripheral radial nerve palsy, when the dropped paretic wrist is supinated, the hand maintains a neutral position and there is a finger palmar flexion due to unopposed pull of the muscles of the flexor compartment of the forearm. In functional wrist drop, during the same manoeuvre, the hand will drop down (hyperextension) with fingers extended.

As the sternocleidomastoid (SCM) muscle has a bilateral innervation, an upper motor neuron lesion should not induce an important weakness and thus in organic hemiparesis the head rotation is usually preserved. The SCM test,${ }^{45}{ }^{46}$ defined as a SCM weakness, has been observed in 24/30 (80\%) functional patients and only $3 / 27(11 \%)$ organic subjects, the weakness being more often ipsilateral to the hemiparesis.

\section{Sensory signs}

The examination of the sensory system relies on the patients report and is subjective in nature. The identification of 'nonorganic' or 'inconsistent' patterns that go against the rule of anatomy has been used. For example, observing an absent joint position sense in the toes and ankles but a Romberg test and tandem walk perfectly well done is highly suggestive of nonorganic sensory deficit. ${ }^{47}$ Similarly, absent upper limb position sense but normal finger-to-nose test with eyes closed is interpreted as an inconsistent sensory deficit. ${ }^{25}$ Observing such inconsistencies has thus been of great importance in the

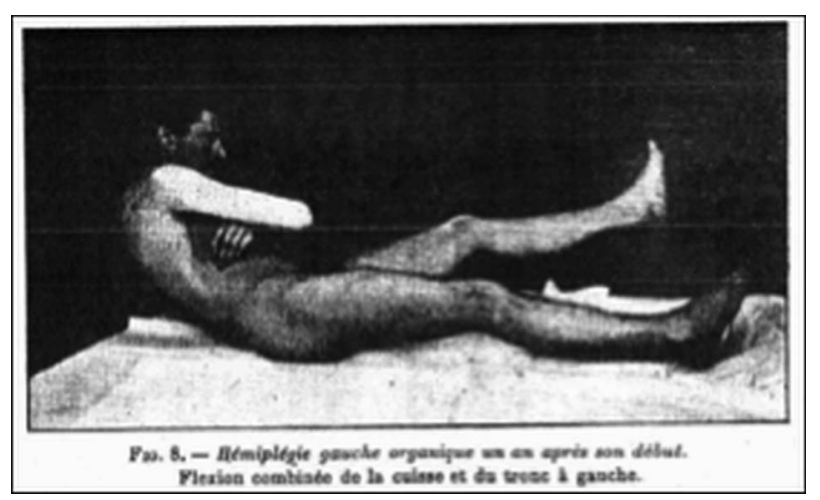

Figure 2 Babinski trunk-thigh test. From Babinski. ${ }^{42}$

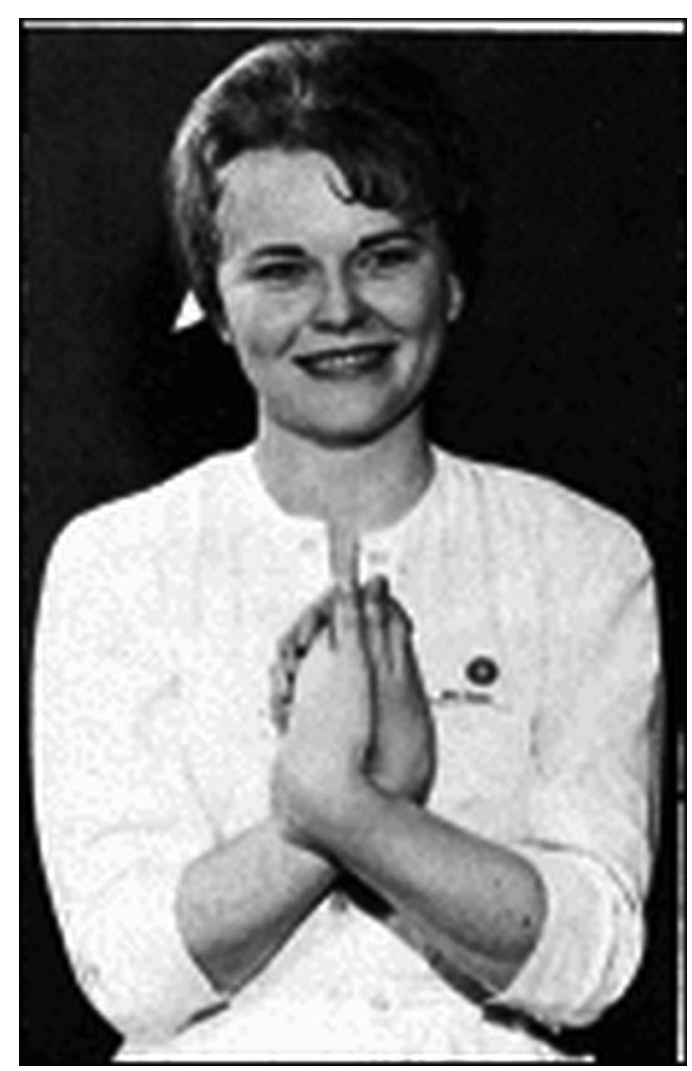

Figure 3 Bowlus-Currier test. From Bowlus. ${ }^{48}$

identification of functional sensory loss and has led to the development of the following tests.

The Bowlus-Currier test ${ }^{48}$ is based on an old trick in children's play where the fingers are 'mixed' (see figure 3 ) in order to bring confusion to the body image. As illustrated in figure 3, all fingers of the left hand (the healthy hand) are aligned except for the left thumb (which is uncrossed and will be aligned with the right hand (the numb hand) fingers). The examiner touches the patient starting on the right little finger up to the thumb: in functional numbness, the patients will report anaesthesia to all the fingers on that line, including the thumb, even though it belongs to the 'healthy side', as it actually is the left thumb. This test has been found positive in 36 hysterical patients and negative in six organic patients. A precise interpretation of the findings and if it was independently tested is however not provided.

The Yes/no test has been suggested to be useful in hysteria. ${ }^{24}$ The 'no' response obtained from a patient when touched on his anaesthetic side, eyes closed, strongly suggests a non-organic deficit, as it proves that some degree of touch perception is preserved. The interpretation of this test is very difficult, and one should resist the simplistic view that it is mere proof of malingering. One could argue that if it represents malingering, it would only be seen in subjects of limited intelligence, ${ }^{25}$ as it defies the logics, even for people with no medical background.

Those signs in functional patients could represent a subtype of inconsistency or a disorder of higher sensory integration and controlled blinded studies are warranted to better define and understand the nature of those intriguing signs.

\section{Abnormal gait signs}

In a series of 228 consecutive functional patients, $60(26 \%)$ were found to have predominant gait disorders. ${ }^{49}$ Most 
frequently observed were ataxic gait (40\%) and hemiparetic gait $(22 \%)$. In ataxic cases, a pattern of 'staggering long to obtain support from opposite walls' was seen as well as 'exaggerated swaying without falling'. In hemiparetic cases, the 'dragging monoplegic leg' (see above) was often seen or the foot was pushed straight ahead without lifting it off the floor. Of note, the hemiparetic arm was often seen to swing normally during walking in those subjects. The author also discloses that astasia-abasia (the inability to stand or walk despite normal leg function in bed), considered to be characteristic of hysteria was not observed in this series.

Another observational series ${ }^{50}$ of 47 patients with functional gait disorder reported a typical discrepancy between an important paresis during examination in bed compared with the capacity of stance and gait (contrary of astasia-abasia) in 23 of the 47 patients $(48.9 \%)$ and two patients $(4.2 \%)$ showed the 'dragging monoplegic leg' (see above).

Careful observation of gait was performed by four coauthors on standardised video recordings of 37 functional patients. ${ }^{51}$ They identified six characteristic clinical features: (1) fluctuation of stance and gait, often in response to suggestion (51\%), (2) excessively slow or hesitating locomotion (35\%), (3) 'psychogenic' Romberg test (constant falls towards or away from the observer irrespective of his position/large amplitude body sway building up after a few seconds/improvement of balance when distracted) (32\%), (4) 'walking on ice' (30\%), (5) 'uneconomic' postures (30\%) and (6) sudden buckling of the knees (27\%). One or more of those signs were present in $97 \%$ of patients. The same authors asked 13 drama students to simulate a gait disorder and the same video recordings were analysed in a nonblinded manner. No comparative statistics were done but some descriptive features are of value: one or more of the above mentioned signs were seen in $8 / 13(61 \%)$ of simulators but on average patients displayed 4.3 signs when simulators displayed 1.5 signs. Moreover, 'psychogenic' Romberg and 'walking on ice' patterns were never observed in simulators.

A similar study focussed on the observation of video-recorded gait patterns of 24 functional patients ${ }^{52}$ and identified three typical features present in $30 \%$ of cases: (1) pseudoataxia (gait with crossed legs or sudden sidesteps), (2) dragging leg, (3) gait with flexed and/or buckling knees. Other phenomena were described as indicative of functional gait, such as pushing of furniture, falling on the physician, flailing arms or 'suffering and strained facial expression'. ${ }^{51}$

In a large cohort of 279 patients suffering from psychogenic movement disorder, ${ }^{53} 118$ (42\%) were found to have gait disorders, either in combination with another psychogenic movement disorders $(102 / 279)$ or isolated $(16 / 279)$. The most frequent signs were: slowing of gait (18\%), dystonic (18\%), bizarre $(12 \%)$, astasia-abasia (12\%) and buckling of the knee $(7 \%)$ when leg dragging was found in only $3 \%$ of cases. In another series of 49 patients with psychogenic movement disorders identified in a consecutive cohort of 1743 neurology patients over 5 years, six (12\%) displayed pure psychogenic gait disorders and among them, four exhibited 'buckling in the knees', one had 'springing gait with exaggerated arm swinging' and one had 'shuffling gait'.

\section{DISCUSSION FOR THE NARRATIVE REVIEW}

This narrative review provides descriptions on 9 additional motor signs, 2 sensory and 13 gait disorder positive signs but is by no means an exhaustive account of existing positive signs (for more please refer to DeJong textbook ${ }^{21}$ ). This highlights how rich and complex the neurological examination is and how making a diagnosis of functional symptoms relies on clinical expertise from the neurologist. The systematic review of validated positive signs showed that most of them carry a very high specificity. Further validation of single signs, as those described in the narrative review might help in the future. In particular, prospective studies, using a blinded design are needed and extra caution should be made to ensure that the criteria used for diagnosis and group attribution of subjects are independent of the outcome measure (the tested sign). Also, for each individual sign, an evaluation of the inter-rater reliability has to be established. The next step will be to combine several of these signs and define which are correlated and which bring independent diagnostic prediction value. This will be of importance for weakness, sensory and gait disorders, as discussed in this review, and functional movement disorders and non-epileptic seizure might benefit from better validated clinical signs. Even if both presentations can use laboratory-supported features, these are still in the development phase $^{11}$ or showed only moderate reliability. ${ }^{12}$

Future work should thus aim at refining the neurological examination by further validating these 'positive signs' and special efforts should be made to spread their standardised use and appropriate teaching. Indeed, the value and interobserver reliability of the neurological examination depends on the level of teaching. ${ }^{54}$ This, however, will not be the sole solution to comply with the new DSM-V criteria, as the clinical evaluation of a neurological patient also takes into account the history. It has been shown that the physical interpretation of the plantar reflex, for example, greatly varies according to the history ${ }^{55}$; clinicians classified the same video as positive when primed with a history suggesting corticospinal involvement and negative when the history did not. Also, when no history is available, neurological signs tend to have a moderate interobserver reliability. ${ }^{56}$ The way functional patients describe their symptoms, when doctors take history, has been shown to also have specific features. ${ }^{57}$ So, in the future an integrative approach, merging history 'positive features' and clinical 'positive signs' might provide evidence-based reliable clinical diagnostic criteria for $\mathrm{CD}$ (functional symptom disorder).

Contributors CD and SA designed the study, completed the review process, extracted and analysed the data. CD wrote a draft of the manuscript. SA and MH critically reviewed the manuscript.

Funding This work was supported by the Swiss National Research Foundation (advanced researcher grant PASMP3_132527 for SA) and the Bourse ProFemme (for SA) from Lausanne University.

Competing interests None.

Provenance and peer review Not commissioned; externally peer reviewed.

\section{REFERENCES}

1 APA. Diagnostic and statistical manual of mental disorders: DSM-IV. Washington, DC: American Psychiatric Association, 1994.

2 World Health Organization. ed. The ICD-10. Classification of mental and behavioural disorders. Geneva: The International Classification of Diseases, 1992.

3 Freud S. ed. Studies in hysteria. London: Hogarthe Press, 1895.

4 Kanaan RA, Carson A, Wessely SC, et al. What's so special about conversion disorder? A problem and a proposal for diagnostic classification. Br J Psychiatry 2010;196:427-8

5 Stone J, Edwards MJ. How "psychogenic" are psychogenic movement disorders? Mov Disord 2011;26:1787-8

6 Nicholson TR, Stone J, Kanaan RA. Conversion disorder: a problematic diagnosis. J Neurol Neurosurg Psychiatry 2011;82:1267-73.

7 Stone J, LaFrance WC Jr, Brown R, et al. Conversion disorder: current problems and potential solutions for DSM-5. J Psychosom Res 2011;71:369-76.

8 Gould R, Miller BL, Goldberg MA, et al. The validity of hysterical signs and symptoms. J Nerv Ment Dis 1986;174:593-7.

9 Voon V, Lang AE, Hallett M. Diagnosing psychogenic movement disorders-which criteria should be used in clinical practice? Nat Clin Pract Neurol 2007:3:134-5. 
10 Avbersek A, Sisodiya S. Does the primary literature provide support for clinical signs used to distinguish psychogenic nonepileptic seizures from epileptic seizures? J Neurol Neurosurg Psychiatry 2010;81:719-25.

11 Schwingenschuh P, Katschnig P, Seiler S, et al. Moving toward "laboratory-supported" criteria for psychogenic tremor. Mov Disord 2011;26:2509-15.

12 Benbadis SR, LaFrance WC Jr, Papandonatos GD, et al. Interrater reliability of EEG-video monitoring. Neurology 2009;73:843-6.

13 McWhirter L, Stone J, Sandercock P, et al. Hoover's sign for the diagnosis of functional weakness: a prospective unblinded cohort study in patients with suspected stroke. J Psychosom Res 2011;71:384-6.

$1450 n o o$ M. Abductor sign: a reliable new sign to detect unilateral non-organic paresis of the lower limb. J Neurol Neurosurg Psychiatry 2004;75:121-5.

15 Tinazzi M, Simonetto $S$, Franco $L$, et al. Abduction finger sign: a new sign to detect unilateral functional paralysis of the upper limb. Mov Disord 2008;23:2415-19.

16 Rolak LA. Psychogenic sensory loss. J Nerv Ment Dis 1988;176:686-7.

17 Okun MS, Rodriguez RL, Foote KD, et al. The "chair test" to aid in the diagnosis of psychogenic gait disorders. Neurologist 2007;13:87-91.

18 Yugué I, Shiba K, Ueta T, et al. A new clinical evaluation for hysterical paralysis. Spine (Phila Pa 1976) 2004;29:1910-13;discussion 1913.

19 Ziv I, Djaldetti R, Zoldan Y, et al. Diagnosis of "non-organic" limb paresis by a novel objective motor assessment: the quantitative Hoover's test. J Neurol 1998;245:797-802

20 van der Ploeg RJ, Oosterhuis HJ. The "make/break test" as a diagnostic tool in functional weakness. J Neurol Neurosurg Psychiatry 1991:54:248-51.

21 Stone J, Warlow C, Sharpe M. The symptom of functional weakness: a controlled study of 107 patients. Brain 2010;133(Pt 5):1537-51.

22 Chabrol H, Peresson G, Clanet M. Lack of specificity of the traditional criteria for conversion disorders. Eur Psychiatry 1995;10:317-19.

23 Baker JH, Silver JR. Hysterical paraplegia. J Neurol Neurosurg Psychiatry 1987;50:375-82

23a Knutsson E, Martensson A. Isokinetic measurements of muscle strength in hysterical paresis. Electroencephalography and Clinical Neurophysiology 1985;61:370-4.

23b Koehler P. Freud's Comparative Study of Hysterical and Organic Paralyses. Archives of Neurology 2003;60:1646-50.

24 Stone J, Zeman A, Sharpe M. Functional weakness and sensory disturbance. I Neurol Neurosurg Psychiatry 2002;73:241-5.

25 Magee KR. Hysterical hemiplegia and hemianesthesia. Postgrad Med 1962:31:339-45.

26 Toth C. Hemisensory syndrome is associated with a low diagnostic yield and a nearly uniform benign prognosis. J Neurol Neurosurg Psychiatry 2003;74:1113-16.

27 Critchley M. Psychiatric symptoms and parietal disease: differential diagnosis. Proc $R$ Soc Med 1964:57:422-8.

28 Todd RB. Clinical lectures on paralysis, certain diseases of the brain, and other affections of the nervous system. 2nd edn. vol. Lecture I, Churchill J. London: Churchill, 1856:20.

29 Blocq PO. Sur une affection caractérisée par de l'astasie et d'abasie. Vol 43. Paris: Progrès Médical, 1888.

30 Carson AJ, Stone J, Warlow C, et al. Patients whom neurologists find difficult to help. J Neurol Neurosurg Psychiatry 2004;75:1776-8.

31 Slater ET, Glithero E. A follow-up of patients diagnosed as suffering from "hysteria". J Psychsom Res 1965:9:9-13.

32 Stone J, Carson A, Duncan R, et al. Symptoms 'unexplained by organic disease' in 1144 new neurology out-patients: how often does the diagnosis change at follow-up? Brain 2009;132(Pt 10):2878-88.
33 Koehler PJ, Okun MS. Important observations prior to the description of the Hoover sign. Neurology 2004;63:1693-7.

34 Babinski J. De la pronation de la main dans l'hémiplégie organique. Rev Neurol (Paris) 1907;15:755

35 Teitelbaum IS, Eliasziw M, Garner M. Tests of motor function in patients suspected of having mild unilateral cerebral lesions. Can J Neurol Sci 2002;29:337-44.

36 Anderson NE, Mason DF, Fink JN, et al. Detection of focal cerebral hemisphere lesions using the neurological examination. J Neurol Neurosurg Psychiatry 2005;76:545-9.

37 Hawkes CH. Diagnosis of functional neurological disease. Br I Hosp Med (Lond) 1997:57:373-7.

38 Marcus $\mathrm{H}$, Aldam P, Lennox $\mathrm{G}$, et al. Medically unexplained neurological symptoms. JRSM Short Rep 2010;1:25.

39 Greer $S$, Chambliss L, Mackler L, et al. Clinical inquiries. What physical exam techniques are useful to detect malingering? J Fam Pract 2005;54:719-22.

40 Reeves RR, Bullen JA. Misuse of the face-hand test for psychogenic neurologic deficits. I Clin Psychiatry 1994;55:363.

41 Barré J. La manoeuvre de la jambe; Nouveau signe objectif des paralysies ou parésis dues aux perturbations du faisceau pyramidal. La Presse Médicale 1919;79:793-5.

42 Babinski J. Diagnostic différentiel de l'hémiplégie organique et de l'hémiplégie hystérique. Gazette des Hôitaux de Paris 1900;73:533-7.

43 Keane JR. Wrong-way deviation of the tongue with hysterical hemiparesis. Neurology 1986;36:1406-7.

44 Sethi NK, Sethi PK, Torgovnick J. Supine catch sign—a simple clinical test to differentiate between true and false (pseudo) radial nerve palsy. Clin Neurol Neurosurg 2010;112:441-2.

45 Diukova GM. (Weakness of the sternocleidomastoid muscle: a diagnostic test in hysterical paralysis). Zh Nevrol Psikhiatr Im S S Korsak 1999;99:56-9.

46 Diukova G. Sternocleidomastoid (SCM) muscle test in patients with hysterical and organic paresis. J Neurol Sci 2001;187(Suppl 1)(PO312):S109.

47 Hayes MW, Graham S, Heldorf $\mathrm{P}$, et al. A video review of the diagnosis of psychogenic gait: appendix and commentary. Mov Disord 1999;14:914-21.

48 Bowlus WE, Currier RD. A test for hysterical hemianalgesia. N Engl I Med 1963;269:1253-4.

49 Keane JR. Hysterical gait disorders: 60 cases. Neurology 1989;39:586-9.

49a Knapp PC. Astasia-Abasia. The Journal of Nervous and Mental Diseases 1891; XVII:673-701.

50 Ehrbar R, Waespe W. (Functional gait disorders). Schweiz Med Wochenschr 1992;122:833-41.

51 Lempert T, Brandt T, Dieterich $M$, et al. How to identify psychogenic disorders of stance and gait. A video study in 37 patients. J Neurol 1991;238:140-6.

52 Diukova GM, Stoliarova AV. (Psychogenic disorders of stance and gait as seen in videotaping). Zh Nevrol Psikhiatr Im S S Korsak 2001;101:13-18.

53 Baik JS, Lang AE. Gait abnormalities in psychogenic movement disorders. Mov Disord 2007;22:395-9.

54 Hansen $\mathrm{M}$, Christensen PB, Sindrup $\mathrm{SH}$, et al. Inter-observer variation in the evaluation of neurological signs: patient-related factors. J Neurol 1994;241:492-6.

55 Van Gijn J, Bonke B. Interpretation of plantar reflexes: biasing effect of other signs and symptoms. J Neurol Neurosurg Psychiatry 1977;40:787-9.

56 Hansen $M$, Sindrup SH, Christensen PB, et al. Interobserver variation in the evaluation of neurological signs: observer dependent factors. Acta Neurol Scand 1994;90:145-9.

57 Schwabe M, Howell SJ, Reuber M. Differential diagnosis of seizure disorders: a conversation analytic approach. Soc Sci Med 2007;65:712-24. 


\title{
JNNP
}

\section{The value of 'positive' clinical signs for weakness, sensory and gait disorders in conversion disorder: a systematic and narrative review}

Corinna Daum, Monica Hubschmid and Selma Aybek

J Neurol Neurosurg Psychiatry published online March 6, 2013

doi: 10.1136/jnnp-2012-304607

Updated information and services can be found at:

http://jnnp.bmj.com/content/early/2013/03/05/jnnp-2012-304607.full.html

\begin{abstract}
These include:
Data Supplement "Supplementary Data"

http://jnnp.bmj.com/content/suppl/2013/03/04/jnnp-2012-304607.DC1.html

References This article cites 52 articles, 13 of which can be accessed free at: http://jnnp.bmj.com/content/early/2013/03/05/jnnp-2012-304607.full.html\#ref-list-1

$\mathbf{P}<\mathbf{P} \quad$ Published online March 6, 2013 in advance of the print journal.

Email alerting

Receive free email alerts when new articles cite this article. Sign up in service the box at the top right corner of the online article.
\end{abstract}

Topic Articles on similar topics can be found in the following collections Collections Somatoform disorders (33 articles)

Advance online articles have been peer reviewed, accepted for publication, edited and typeset, but have not not yet appeared in the paper journal. Advance online articles are citable and establish publication priority; they are indexed by PubMed from initial publication. Citations to Advance online articles must include the digital object identifier (DOIs) and date of initial publication.

To request permissions go to:

http://group.bmj.com/group/rights-licensing/permissions

To order reprints go to:

http://journals.bmj.com/cgi/reprintform

To subscribe to BMJ go to:

http://group.bmj.com/subscribe/ 
Notes

Advance online articles have been peer reviewed, accepted for publication, edited and typeset, but have not not yet appeared in the paper journal. Advance online articles are citable and establish publication priority; they are indexed by PubMed from initial publication. Citations to Advance online articles must include the digital object identifier (DOIs) and date of initial publication.

To request permissions go to:

http://group.bmj.com/group/rights-licensing/permissions

To order reprints go to:

http://journals.bmj.com/cgi/reprintform

To subscribe to BMJ go to:

http://group.bmj.com/subscribe/ 